East African Medical Journal Vol. 86 No. 9 September 2009

CONGENITAL CYSTIC ADENOMATOID MALFORMATION: CASE REPORT.

K. C. Wafula, MBChB, MMed Consultant, Paeditrician and S. Waa, MBChB, MMed (Rad), Radiologist and Instructor, Department of Radiology, Aga Khan University Hospital Nairobi, P. O Box 30270-00100, Nairobi, Kenya

Request for reprints to: Dr. S. Waa, Aga Khan University Hospital Nairobi, P. O. Box 30270-00100, Nairobi, Kenya

\title{
CONGENITAL CYSTIC ADENOMATOID MALFORMATION: CASE REPORT
}

\author{
K. C. WAFULA and S. WAA
}

\begin{abstract}
SUMMARY
Congenital cystic adenomatoid malformation of the lung is a rare lesion that typically manifests as severe progressive respiratory distress in the neonate secondary to expansion of the affected lung. We present a neonate in whom this condition was diagnosed and managed at the Aga Khan University Hospital. In presenting this patient, we hope to highlight the radiological aspects of this condition which, with prompt recognition and management and in the absence of pulmonary hypoplasia, foetal hydrops or other congenital anomalies, has a favourable prognosis.
\end{abstract}

\section{INTRODUCTION}

Congenital cystic adenomatoid malformation (CCAM) is defined as a mass of abnormal solid or cystic pulmonary tissue in which there is a proliferation of bronchial structures at the expense of alveolar development (1). CCAM was initially described as a distinct entity by $\mathrm{Ch}^{\prime}$ in and Tang (2) in which they reported one case and reviewed ten previously reported cases with adenomatoid proliferation of the lungs associated with hydrops in stillborn or premature neonates. CCAM accounts for $25 \%$ of congenital lung lesions. It has a male preponderance but no clear racial predilection. It involves a single lobe $95 \%$ of the time, is multi-lobar in $10 \%$ and bilateral in $2 \%$. Right middle lobe cases are the least common. Seventy per cent present in first month of life (3).

\section{CASE REPORT}

A five day old male infant presented to a paediatric clinic at Aga Khan University Hospital with complaints of poor feeding. The neonate's mother estimated that in the three days after discharge from hospital, the intake totaled $100 \mathrm{ml}$ of breast milk. She also observed that the child occasionally made grunting sounds. In the 24 hours prior to presenting to the clinic, the patient had not passed urine.

The patient had been delivered by Caesarian section following failed induction. Birth weight was 2.9 kilograms. No immediate complication occurred, mother and child were discharged home two days post delivery.
On examination at admission, the baby was ill looking, irritable and afebrile. The anterior fontanelle was flat. Respiratory rate was increased at 72 breaths per minute. Vesicular breath sounds were heard on auscultation of the chest. While still undergoing examination, the patient suffered a cardiorespiratory arrest. At the time, this was thought to be due to hypovolemia. Following resuscitation, it was observed that the respiratory rate remained high and that oxygen saturation on room air was below $90 \%$. A chest radiograph was then requested.

This demonstrated right hemi thorax hyperluscency with shift of the mediastinum to the left as well as inversion of the diaphragm.

Figure 1

Pre-operative chest radiograph

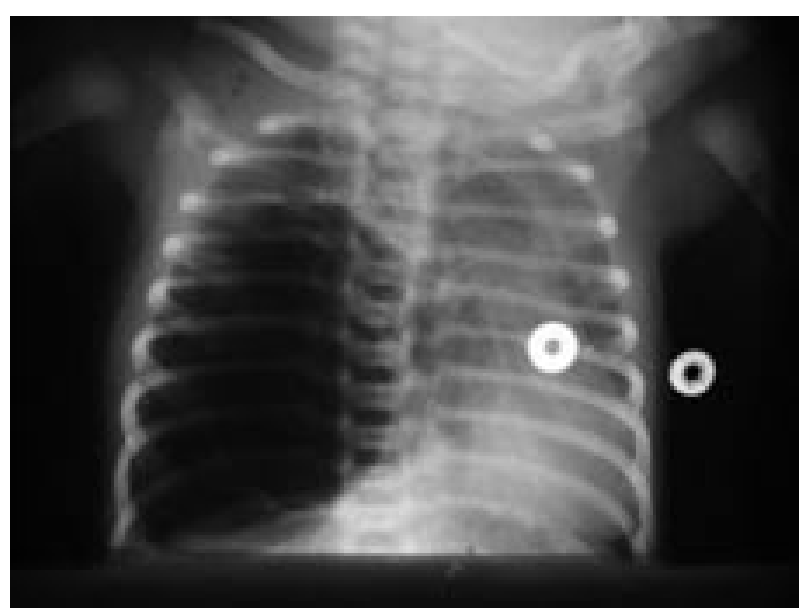

CXR done at the time of admission, demonstrating right hemi thorax luscency with shift of the mediastinum to the left as well as inversion of the diaphragm 
As the patient had undergone a cardiorespiratory resuscitation, and tension pneumothorax could not be definitely excluded on the radiograph, a CT of the chest was requested (Figure $2 \mathrm{a}$ and $\mathrm{b}$ ).

\section{Figure 2}

Pre-operative CT chest

(a)

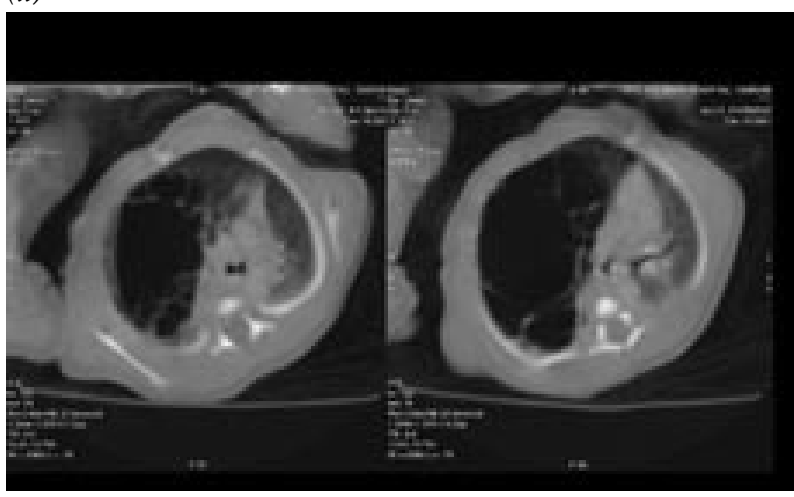

(a) Communicating cystic spaces dominating the right lower lobe. Normal parenchyma within right middle lobe and marked shift of mediastinum to the left side are redemonstrated.

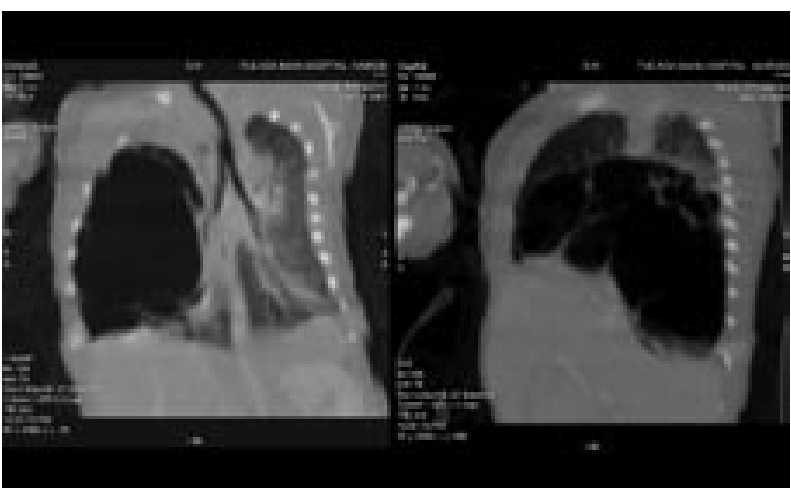

(b) Re-demonstration of communicating cystic spaces on coronal reformat. Communication with lower lobe bronchus is seen

This demonstrated large cystic spaces occupying the right mid and lower zones, communicating with the right lower bronchus. The CT examination was reported as congenital lobar emphysema with a differential diagnosis of congenital cystic adenomatoid malformation. Pneumothorax was definitely excluded.

Following review by a cardiothoracic surgeon, a decision was reached to carry out a thoracotomy. Aright lower lobectomy was carried out. The resected lobe measured $6 \mathrm{~cm}$ by $4 \mathrm{~cm}$ by $1 \mathrm{~cm}$ and had a $2.5 \mathrm{~cm}$ bullous area.
On the first post operative day, the patient had oxygen saturation of $99 \%$ on one liter of oxygen per minute by mask, was well hydrated and passing urine. The chest was clear and a chest radiograph carried out showed an expanded right upper and middle lobe (Figure 3).

Figure 3

Post operative chest radiograph

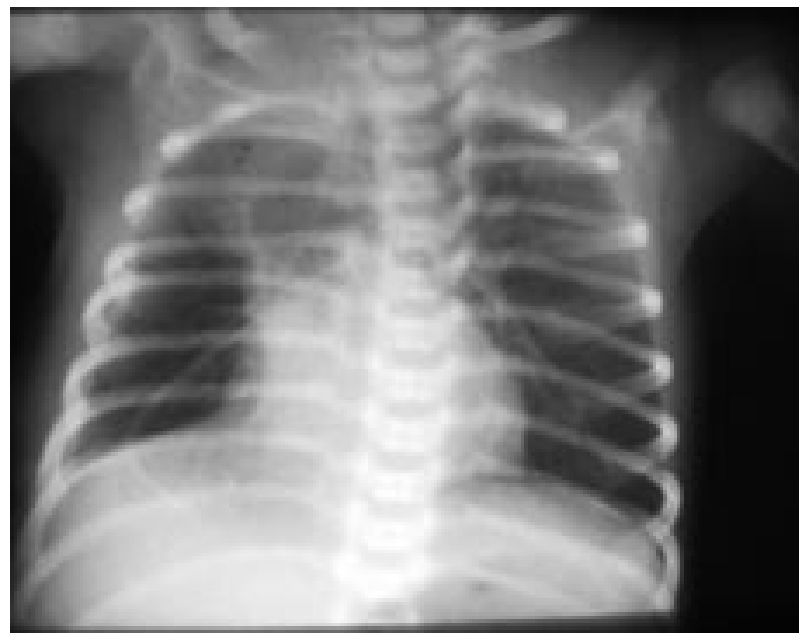

Chest radiograph taken on sixth post operative day following removal of chest drains showing right upper lobe atelectasis and bilateral basal air trapping. The rest of the lungs are clear.

Recovery was uneventful and the patient was discharged home on the fifth post operative day. Our patient was well and demonstrated normal growth and development on follow up to one year after the operation.

Histology demonstrated intercommunicating gland like cystic spaces lined by pseudostratified columnar epithelium with the rest of the lung showing marked congestion. The pathology report gave a conclusion of congenital cystic lung disease favouring solitary cystic adenomatoid transformation.

\section{DISCUSSION}

Congenital cystic adenomatoid malformation is increasingly being diagnosed in utero as the use of obstetric ultrasonography grows. Unfortunately, our patient did not have prenatal scans at our hospital and the images were not available for review. In retrospect, it would have been interesting to see if the condition could have been diagnosed then. 
Prenatally, the challenge is mostly to differentiate this condition from congenital diaphragmatic hernia. To do this, the diaphragm would have to be visualised and for this reason, obstetric MRI is sometimes required.

The clinical presentation is typically of progressive respiratory distress after delivery as inhaled air gets trapped in the cystic lung tissue and compresses normal lung. Plain radiography is sufficient to make the diagnosis in many cases.

In this case, it was difficult to differentiate between congenital lobar emphysema, congenital cystic adenomatoid malformation and tension pneumothorax on radiography. For this reason, a CT of the chest was carried out and this demonstrated cystic over expansion of the right lung base. Distinguishing between CCAM, especially type 1 , which has a large cyst, and congenital lobar emphysema is not always possible as in our case. Fortunately, the surgical management of the two conditions in the symptomatic patient remains excision of the affected lobe.

The pathophysiological basis for this condition is abnormal endodermal or mesodermal differentiation during the fifth to seventh weeks in utero. This results in focal arrest in foetal lung development causing poorly developed intrapulmonary bronchial system. The molecular basis is thought to be excessive platelet derived growth factor $\mathrm{BB}$ which leads to increased cell proliferation and decreased cell apoptosis in utero. The condition is part of the continuum of pulmonary developmental anomalies described by Panicek $e t$ al (4). Traditionally, the condition is classified into three types according to Stocker et al (5). Type 1 makes up 50\%. In this type, multiple large cysts over $2 \mathrm{~cm}$ in size with a single dominant cyst are seen. These communicate with the bronchial tree of the affected lobe.

Cysts are lined by tall ciliated columnar to pseudostratified columnar epithelium and walls contain abundant elastic tissue. Gross and histological appearances indicated that our patient had this type of CCAM. In the symptomatic patient with this type of CCAM, resection of the affected lobe generally has an excellent prognosis.

Type 2 makes up 40\% and consists of multiple cysts between $0.5 \mathrm{~cm}$ and $2 \mathrm{~cm}$ which communicate with bronchial tree and resemble dilated bronchioles. The lining varies from ciliated cuboidal to columnar epithelium. In $30 \%$ of cases, type 2 CCAM is associated with renal, cardiac, gastrointestinal and osseous anomalies. Forty per cent of cases of extra lobar sequestration are associated with type 2 CCAM.

Type 3 makes up 10\% and commonly appears as a bulky, firm mass with tiny cysts less than $0.5 \mathrm{~cm}$ in diameter lined by cuboidal epithelium. It is associated with polyhydramnios and foetal anasarca.

The initial reports of CCAM by Ch'in and Tang (2) were probably that of type three. This was described as solid appearing lung mass consisting of adenomatoid / gland-like proliferation of terminal respiratory structures in neonates.

Large lesions may compromise normal development of lungs in utero leading to stillbirth or neonatal death. CCAM is a recognised cause of non-immune foetal hydrops. In the symptomatic patient, resection of the affected lobe generally has an excellent prognosis.

In the asymptomatic patient, resection is still usually advised due to risk posed by recurrent infections and malignant transformation $(6,7)$.

In conclusion, CCAM is a condition that can cause progressive respiratory distress requiring immediate surgical intervention. Understanding the morphologic characteristics of this lesion may lead to the recognition of its varied radiologic appearances, allowing early diagnosis and optimal patient management.

\section{ACKNOWLEDGEMENTS}

The authors thank the patient's family for allowing publication of this case report; Dr. J. Munene and the surgical team at the Aga Khan University Hospital, Nairobi, who played a major part in management of this patient.

\section{REFERENCES}

1. Caffey's Pediatric Diagnostic Imaging, 10th edition. 2004; Vol. 1: pg 905.

2. Ch'in, K. Y. and Tang, M.Y. Congenital adenomatoid malformation of one lobe of a lung with general anasarca. Arch. Pathol. 1949; 48: 221-229.

3. Mandell, G. Congenital cystic adenomatoid malformation. E-Medicine from Web MD. www. emedicine.com/radio/TOPIC186.HTM.

4. Panicek, D.M.,Heitzmann, E.R. and Randall, P.A.The continuum of pulmonary developmental anomalies. Radiographics. 1987;7:747-772. 
5. Stocker, J.T., Madewell, J.E. and Drake, R.M. Congenital cystic adenomatoid malformation of the lung: classification and morphologic spectrum. Hum. Pathol. 1977; 8:155-171.

6. Benjamin, D.R. and Cahill, J.L. Bronchioloalveolar carcinoma of the lung and congenital cystic adenomatoid malformation. Am. J. Clin. Pathol. 1991; 95: 889-892.
7. Granata, C., Gambini, C., Balducci, T., et al. Bronchioloalveolar carcinoma arising in congenital cystic adenomatoid malformation in a child. A case report and review on malignancies originating in congenital cystic adenomatoid malformation. Pediatr. Pulmono. 1998; 25: 62-66. 